\title{
Improving Visual Communication of Weather Forecasts with Rhetoric
}

\author{
K. M. Lambrecht, B. J. Hatchett, L. C.Walsh, M. Collins, and Z. Tolby
}

E ffective communication of weather forecasts and related hazards, particularly levels of forecast confidence, to the general public represents a continual challenge for operational meteorologists. The approach to communication of high-impact weather events has immediate implications for life and property as well as developing longer-term community resilience to extreme events. Building on research that suggests that bringing together multiple types of expertise is important to science communication (e.g., Fischhoff 2013), we sought an interdisciplinary approach, combining the work of meteorology and rhetoric to strengthen communication with public audiences. Using a rhetorical framework reveals how we can build trust with the public by 1) inviting audience participation, 2) providing a way for users to distribute weather information to others, and 3) encouraging interactions that increase solidarity with the public. Our initial results suggest that visual communication incorporating the rhetorical concept of "commonplaces" used by the public can support effective National Weather Service communication.

Commonplaces are the expressions of beliefs, values, and norms that construct community

AFFILIATIONS: LAMBRECHT AND WALSH-Department of English, University of Nevada, Reno, Nevada; HATCHETT—Division of Atmospheric Sciences, and Western Regional Climate Center, Desert Research Institute, Reno, Nevada; Coluins-Office of Education, Desert Research Institute, Reno, Nevada; TolbYNational Weather Service, Reno, Nevada CORRESPONDING AUTHOR: Benjamin J. Hatchett, benjamin.hatchett@gmail.com

DOI:10.II75/BAMS-D-18-0186.|

(C)2019 American Meteorological Society

For information regarding reuse of this content and general copyright information, consult the AMS Copyright Policy. attitudes toward subjects like weather or natural hazard forecasts (Locke 1999; Prelli 1990). For example, the decision to change driving routes to avoid hazardous snow communicates a value of keeping oneself safe, a commonplace that is shared across many members of the community. Understanding community values and using those commonplaces in forecasting is a way to build what Earle (2010) would call "relational trust" because using shared language in weather communication builds a foundation of resilience between meteorologists and the public, helping to sustain the relationship through moments of uncertainty.

The National Weather Service (NWS) has experienced a rapid evolution of forecast communication since it began disseminating forecasts, warnings, and advisories on social media in 2011 as part of the "Weather Ready Nation" initiative. This initiative furthers previous research that suggests that encouraging public involvement is important in science communication (National Academies of Sciences, Engineering, and Medicine 2017) and that science is communicated within a larger network of social concerns (Maynard and Scheufele 2016). In addition to using outlets such as Facebook (FB) and Twitter to disseminate traditional weather warning products, social media has given NWS forecasters an opportunity to try new communication techniques and receive rapid feedback on the potential effectiveness of new strategies. Public followers frequently post comments in response; these posts often contain insights into the values, opinions, and beliefs that reflect their attitudes toward science and forecasting uncertainty. Previous studies of public attitudes toward weather forecasts have treated uncertainty as technical uncertainty-for example, probability and likelihood (Gigerenzer et al. 2005; Morss et al. 2008; National Research Council 2006). Meanwhile, rhetoricians have demonstrated that for public audiences, uncertainty also means risk, doubt, value, and 

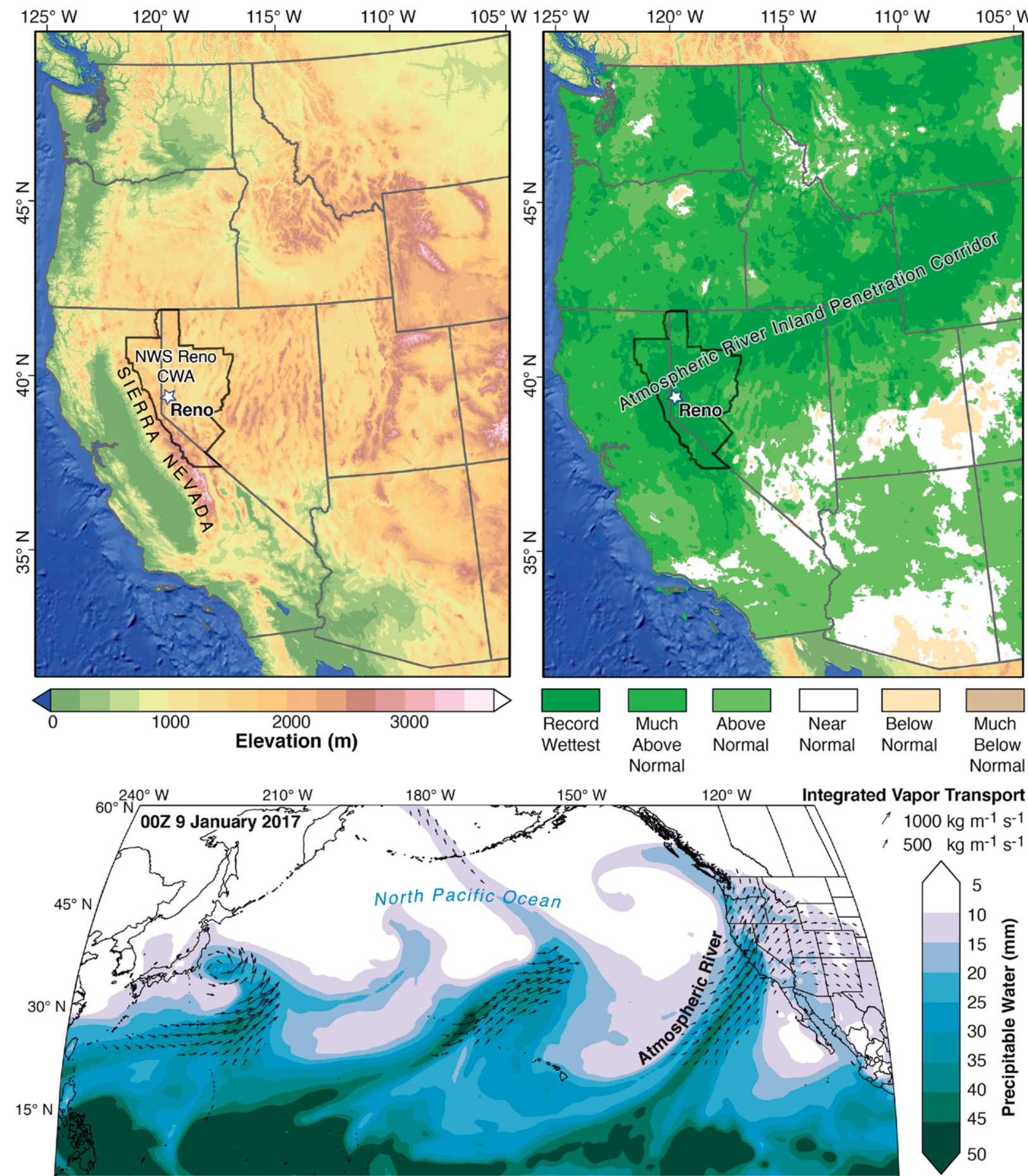

FIG. I. (top left) Topography of the western United States (shaded; units in $m$ ) and the Reno NWS county warning area (CWA; thick gray outline). (top right) Precipitation anomalies estimated for the western United States during the period Oct 2016-Apr 2017 provided by WestWide Drought Tracker (Abatzoglou et al. 2017). A favored inland penetration corridor for atmospheric rivers identified by Rutz et al. (2015) is shown. (bottom) Examples of atmospheric rivers in the North Pacific from 0000 UTC 9 Jan 2017. Integrated vapor transport and precipitable water are from the Modern-Era Retrospective Analysis for Research and Applications, version 2 (MERRA-2; Gelaro et al. 2017) with atmospheric river conditions (vectors) identified using the Guan and Waliser (2015) algorithm applied to MERRA-2. 
conviction (Babrow 2001; Brashers 2001; Walsh and Walker 2016). Rhetoric, which developed at roughly the same time as philosophy in ancient Greece, is a discipline that studies how communication forms communities. Although Plato dismissed it as mere verbal manipulation, rhetoric has long since been studied and practiced as an ethical art of communication that can benefit community and individual relationships. Given this central role in communicative practice, Goodnight (1982, p. 215) defines rhetoric as the "creative resolution and resolute creation of uncertainty." In other words, rhetoric was developed expressly to cope with uncertainty in public life. This rationale makes rhetoric directly relevant to the study of the public reception of weather forecasts.

Goodnight identified three major types of uncertainty that organize public debates about subjects like weather hazards: personal (having to do with commitment and personal risks), technical (related to probability and likelihood, as defined above, in addition to the reliability of scientific methods), and public (indexing political stances and widely shared norms around freedom and justice). Studying public responses to weather forecasts (e.g., Casteel and Downing 2013; Ash et al. 2014) in terms of all three of these types of uncertainty can make weather forecast communication more effective in meeting public needs and aligning the values and concerns of scientists and community members.

Given this background, we hypothesized that a) a survey of public responses to weather forecast posts on NWS Reno's FB page would reveal that technical uncertainty was not the greatest public concern and b) that posts that incorporated community-generated commonplaces would receive the greatest response from the public. To explore these hypotheses, we focused on the NWS Reno area of forecast responsibility (Fig. 1, top left). The NWS Reno office had already begun experimenting with nontraditional (for a government organization) communication strategies and wanted a way to measure the effectiveness of their approach. This area is located in the lee of the Sierra Nevada and along a preferential corridor for atmospheric rivers, which are long, narrow corridors of strong horizontal water vapor transport typically located in the warm sector of midlatitude cyclones (American Meteorological Society 2018; Rutz et al. 2015; Fig. 1, top right and bottom). Atmospheric rivers bring a wide variety of cool season weather extremes such as flooding, heavy snow, and downslope windstorms. Often, these extremes occur in close geographical and temporal proximity. To analyze public responses to weather events, we performed a two-stage rhetorical evaluation composed of qualitative coding and topical analysis (Miller 1987; Saldaña 2009) on 470 NWS Reno FB posts that generated 6,467 public comments. The posts analyzed were from January to May 2017. This period overlapped with a record wet period in the NWS Reno region during the cool season of October-April (Fig. 1, top right). Many high-impact events during 2016/17 (Sterle et al. 2019) created challenges for the region's approximately 500,000 residents and thus lively discussions about weather on social media.

Identifying commonplaces in public commentary provides meteorologists a way of uncovering values hidden in language, showing that they listen to the needs of the public and tailor their messages to their audience and place-based concerns and values. Because every mode of communication expresses the values or norms of the community that created it, it is possible to work backward from commonplaces to uncover community norms and values. In this way, using commonplaces is a way of "speaking the language" of the community, acknowledging that a one-size-fits-all or "standardized" communication strategy isn't the best way to build solidarity with the purveyor of information on extreme weather. For this reason, we began by coding FB comments for community commonplaces and for the type of uncertainty indexed by each commonplace. Lambrecht and Walsh performed this initial coding. For example, the comment "Grandma, be careful driving over the pass" expressed the commonplace It's important to watch out for family, which indexed personal uncertainty relating to commitment and personal risks. The comment in response to flood warnings, "How sure are you guys that we'll hit 10,000 cubic feet per second this afternoon?" expressed the commonplace The confidence of weather forecasts is crucial information, which indexed technical uncertainty, having to do with the reliability of the information or methods. Finally, the comment "Blame Democrats for the Oroville dam failure" expressed the commonplace Politicians neglect infrastructure, which indexed public uncertainty, or that which deals with common political values and norms. In addition to this coding process, "tags" of friends/family members, the number of reactions, the number of shares, and medium of the post (images, videos, infographics, or plain text) were also noted for each comment. 


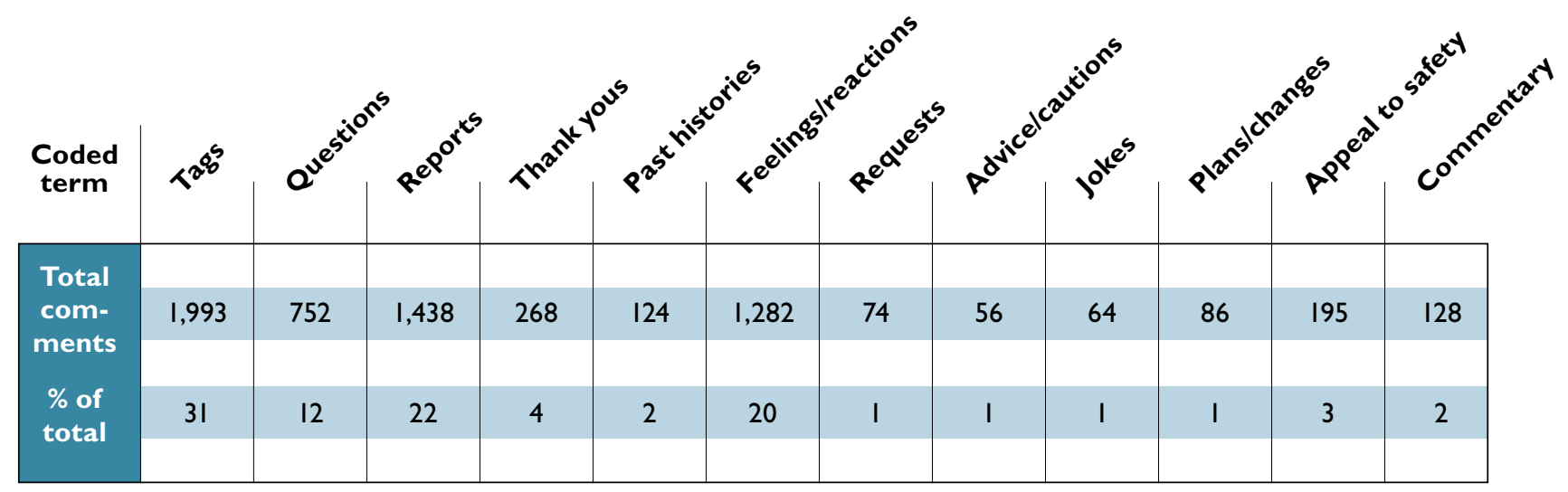

TABLE I. Primary coded terms from stage one of the two-stage rhetorical analysis.

After this initial analysis, Walsh coded a subset of the posts Lambrecht had coded-those incorporating infographics-using the list of commonplaces Lambrecht had found while also noting the type of uncertainty raised in comments on the infographics. ${ }^{1}$ In this stage, we found that $68 \%$ of coded comments expressed personal uncertainties, compared to only $26 \%$ that engaged with technical uncertainty and $6 \%$ that indexed public uncertainties. These results confirm our first hypothesis and suggest that NWS Reno's FB community engages less with the technical uncertainties of forecasts than it does with personal risks implied in those forecasts. In a related result (Table 1), we found that public comments on NWS FB posts generally do one of four things: tag others to follow the post $(31 \%)$, report the weather from their location (22\%), react either positively or negatively to forecasts (20\%), and ask questions about the current or forecast weather (12\%). The nature of these comments corresponds to the dominance of personal uncertainties, as NWS Reno FB followers use the forecasts as a rhetorical occasion to express concern for and reach out to family and friends. The dominance of tagging and evaluating posts emotionally, along with the dominance of expressions of personal uncertainty, suggest that NWS Reno FB followers are using the platform as much to connect with each other as to calculate the likelihoods and impacts of weather events. Replicating community commonplaces in forecasts strengthens rhetorical connections between NWS and its publics. The relationship between content type and uncertainty type is unclear, but there could be a connection between the dramatization of weather events provided by graphics and a felt sense of personal risk. Because we cannot control for how FB settings "push" more video content into followers' streams versus static images and text-based posts, a statistical comparison would be incomplete. While we did have a large dataset of public comments, factors such as the urgency of weather events, longevity of weather hazards, and constantly changing audience based on number of tags makes comparing the two invalid. More detailed examination of the relationships between content type and uncertainty type is warranted for future research in order to better constrain our results.

Once we had identified the most frequent community commonplaces, we looked to see if posts that incorporated them generated stronger community responses. Two frequent commonplaces were eyewitness confirmation of forecasts (e.g., "I'll believe it when I see it!") and assessments of personal risk (e.g., "Yes, but is it going to snow down here?"). Two examples of graphics employing these commonplaces are provided in Fig. 2 (left and top right), and these graphics generated substantial public engagement. An example of an image from a previous winter that does not employ a commonplace is also provided for comparison (Fig. 2, bottom right). During large atmospheric river events in January 2017 (e.g., Fig. 1, bottom), which followed a severe 5-yr drought, messaging was needed to convey the threat of widespread

\footnotetext{
${ }^{1}$ Although the same codebook of commonplaces was used initially in the second phase of analysis, new codes arose during this phase, as is typical for exploratory rhetorical studies of this nature, so interrater reliability was not calculated. In future studies of the same or a similar dataset from Reno NWS FB, the codebook would likely be stable enough to permit the calculation of interrater reliability using Cohen's Kappa.
} 


\section{High Confidence in Widespread Flooding this Weekend}

This is a once a decade event Flooding may be similar to 2005

This is not a "I'll believe it when I see it" forecast The time to prepare is now!
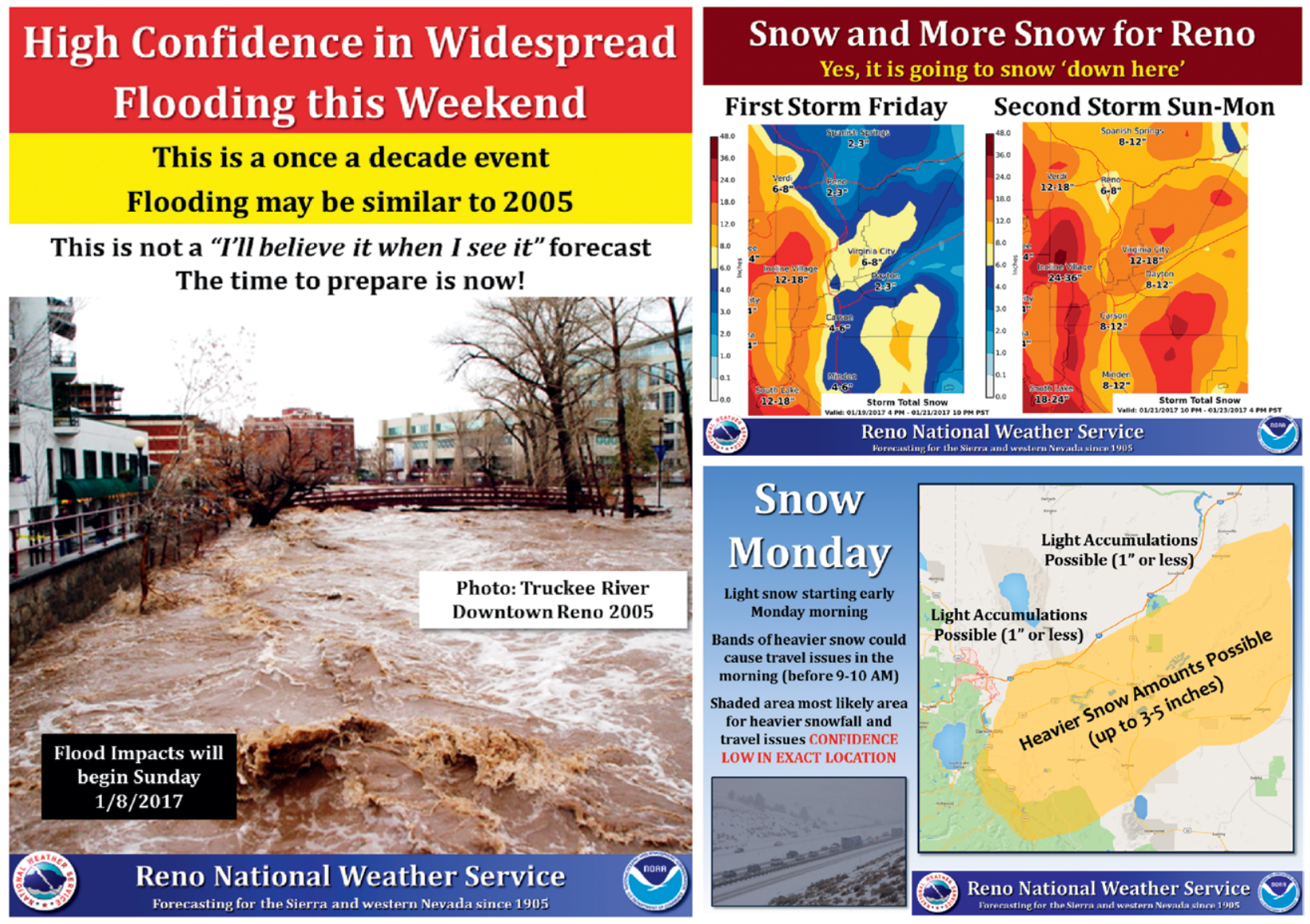

FIG. 2. (left),(top right) Example commonplace-based weather stories produced during winter $2016 / 17$ by the Reno NWS and shared on social media. (bottom right) Example weather story produced during winter 2015/16 that did not include a commonplace.

flooding in the normally arid, rain-shadowed RenoSparks metropolitan area. Although forecast confidence was growing in a high-impact event, forecasters were expecting a skeptical reaction since widespread flooding is a relatively rare phenomenon in the Reno area and one that many new residents in the region likely had not experienced. In addition to the known technique of communicating hazards by comparing the forecast event to a similar past event, they added the headline "This is not an 'I'll believe it when I see it forecast' The time to prepare is now!" to the graphic (Fig. 2, left). The post received 221 reactions, 577 shares, and 94 comments (notably higher than the average of 139 reactions, 415 shares, and 42 comments for technical graphics posted in 2017). Many comments acknowledged a social connection between NWS and its FB community: for example, "Wow, do you know me!" and "OK, I get it." The success of employing this global meteorological commonplace led the Reno NWS to apply the same idea on a more local level for snowfall forecast in the low-lying valley regions. The majority of the population is located in these valleys, where it only snows occasionally. Feet of snow can fall in the higher elevations of the Sierra Nevada with the Reno area receiving little to no snow accumulation, so the public often asks "Is it really going to snow down here [in the valley]?" The commonplace "down here" was added to what became a widely shared and commented forecast graphic (877 shares and 89 comments; Fig. 2, upper right) to communicate that snow would actually accumulate in the valleys and city limits and not just in the mountains in that particular storm event. While we did not have an even enough distribution of samples to perform a statistical comparison of the response rate to posts incorporating community commonplaces versus those without them, the positive reaction to these two posts is promising and suggests a topic for further research. 
Weather communication strategies should invite and encourage public involvement, while bearing in mind the nuances of place and local values. One way to strengthen relationships with consumers of weather information is through shared language: the use of commonplaces offers meteorologists a strategy for identifying with the public in ways that show understanding of the unique contours of the community. Shared language can easily be implemented in any visual communication medium (i.e., videos, plain text, or graphics) to improve communication effectiveness. This strategy allows users to connect weather forecasts with daily life, and they can act as conduits for distribution of weather information by using it in their existing connections with friends and family. Connecting with users in this way may also increase interaction and build trust between NWS information outlets and public audiences. Many previous studies of science communication surrounding climate and weather focus on the difficulty of communicating technical uncertainties but often focus less on the need to address personal and political uncertainties. These overlooked uncertainty types interact in people's decisions to take, or not to take, action in response to a forecast of extreme weather and mediate trust in the agency providing the information. We have presented a framework to identify commonplaces that shape the publics' responses to uncertainties associated with weather forecasts. We recommend operational meteorologists conduct similar surveys of their social-media communities and become more familiar with their own community-generated commonplaces to improve the persuasiveness and effectiveness of forecasts in their specific region.

ACKNOWLEDGMENTS. This research was supported by the Nevada NASA Space Grant Consortium under Award NNX15AI02H and the Desert Research Institute. We greatly appreciate the effort of three anonymous reviewers for their constructive feedback that improved this contribution.

\section{FOR FURTHER READING}

Abatzoglou, J. T., D. J. McEvoy, and K. T. Redmond, 2017: The West Wide Drought Tracker: Drought monitoring at fine spatial scales. Bull. Amer. Meteor. Soc., 98, 1815-1820, https://doi.org/10.1175/BAMS -D-16-0193.1.
American Meteorological Society, 2018: Atmospheric river. Glossary of Meteorology, http://glossary.ametsoc .org/wiki/atmospheric_river.

Ash, K. D., R. L. Schumann, and G. C. Bowser, 2014: Tornado warning trade-offs: Evaluating choices for visually communicating risk. Wea. Climate Soc., 6, 104-118, https://doi.org/10.1175/WCAS-D-13-00021.1.

Babrow, A., 2001: Uncertainty, value, communication, and problematic integration. J. Commun., 51, 553-573, https://doi.org/10.1111/j.1460-2466.2001.tb02896.x.

Brashers, D. E., 2001: Communication and uncertainty management. J. Commun., 51, 477-497, https://doi .org/10.1111/j.1460-2466.2001.tb02892.x.

Casteel, M. A., and J. R. Downing, 2013: How individuals process NWS weather warning messages on their cell phones. Wea. Climate Soc., 5, 254-265, https://doi .org/10.1175/WCAS-D-12-00031.1.

Earle, T. C., 2010: Trust in risk management: A modelbased review of empirical research. Risk Anal., 30, 541574, https://doi.org/10.1111/j.1539-6924.2010.01398.x.

Fischhoff, B., 2013: The sciences of science communication. Proc. Natl. Acad. Sci. USA, 110 (Suppl.), 14 033-14 039, https://doi.org/10.1073/pnas.1213273110. Gelaro, R., and Coauthors, 2017: The Modern-Era Retrospective Analysis for Research and Applications, version 2 (MERRA-2). J. Climate, 30, 5419-5454, https://doi.org/10.1175/JCLI-D-16-0758.1.

Gigerenzer, G., R. Hertwig, E. Van Den Broek, B. Fasolo, and K. V. Katsikopoulos, 2005: "A 30\% chance of rain tomorrow": How does the public understand probabilistic weather forecasts? Risk Anal., 25, 623-629, https://doi.org/10.1111/j.1539-6924.2005.00608.x.

Goodnight, G. T., 1982: The personal, technical, and public spheres of argument: A speculative inquiry into the art of public deliberation. J. Amer. Forensic Assoc., 18, 214-227.

Guan, B., and D. E. Waliser, 2015: Detection of atmospheric rivers: Evaluation and application of an algorithm for global studies. J. Geophys. Res. Atmos., 120, 12 514-12 535, https://doi.org/10.1002/2015JD024257.

Locke, S., 1999: Golem science and the public understanding of science: From deficit to dilemma. Public Understanding Sci., 8, 75-92, https://doi .org/10.1088/0963-6625/8/2/301.

Maynard, A., and D. A. Scheufele, 2016: What does research say about how to effectively communicate about science? The Conversation, https://theconversation .com/what-does-research-say-about-how-to -effectively-communicate-about-science-70244.

Miller, C. R., 1987: Aristotle's "special topics" in rhetorical practice and pedagogy. Rhetoric Soc. Quart., 17, 61-70, https://doi.org/10.1080/02773948709390767. 
Morss, R. E., J. L. Demuth, and J. K. Lazo, 2008: Communicating uncertainty in weather forecasts: A survey of the U.S. public. Wea. Forecasting, 23, 974-991, https:// doi.org/10.1175/2008WAF2007088.1.

National Academies of Sciences, Engineering, and Medicine, 2017: Communicating Science Effectively: A Research Agenda. National Academies Press, $152 \mathrm{pp}$.

National Research Council, 2006: Completing the Forecast: Characterizing and Communicating Uncertainty for Better Decisions Using Weather and Climate Forecasts. National Academies Press, 124 pp., https://doi .org/10.17226/11699.

Prelli, L. J., 1990: Rhetorical logic and the integration of rhetoric and science. Commun. Monogr., 57, 315-322, https://doi.org/10.1080/03637759009376206.
Rutz, J. J., W. J. Steenburgh, and F. M. Ralph, 2015: The inland penetration of atmospheric rivers over western North America: A Lagrangian analysis. Mon. Wea. Rev., 143, 1924-1944, https://doi.org/10.1175/MWR -D-14-00288.1.

Saldaña, J., 2009: The Coding Manual for Qualitative Researchers. Sage, 240 pp.

Sterle, K., B. J. Hatchett, L. Singletary, and G. Pohll, 2019: Hydroclimatic variability in snow-fed river systems: Local water managers' perspectives on adapting to the "new normal." Bull. Amer. Meteor. Soc., https:// doi.org/10.1175/BAMS-D-18-0031.1, in press.

Walsh, L., and K. C. Walker, 2016: Perspectives on uncertainty for technical communication scholars. Tech. Commun. Quart., 25, 71-86, https://doi.org/10.1080 /10572252.2016.1150517.

From roots in radio to graphics-laden TV segments, this history is an entertaining read for anyone fascinated by the public face of weather!

\section{Weather on the Air: A History of Broadcast Meteorology} ROBERT HENSON

From low humor to high drama, Weather on the Air documents the evolution of weathercasts, including the people, technology, science, and show business that combine to deliver the weather to the public. Meteorologist and science journalist Robert Henson has combined decades of research, dozens of interviews, and historical photos to create the first comprehensive history of its kind, featuring:

- Entertainers, scientists, and the long-term drive to professionalize weathercasting

- The complex relations between government and private forecasters

- How climate change science and the Internet have changed the face of today's broadcasts

() 2010, HARDCOVER, 248 PAGES Weather on the Air
A MISTORY OF BROAOCAST MEIEOROLOCG Robert Henson ISBN: 978-1-878220-98-1 AMS CODE: WOTA LIST \$35 MEMBER \$25

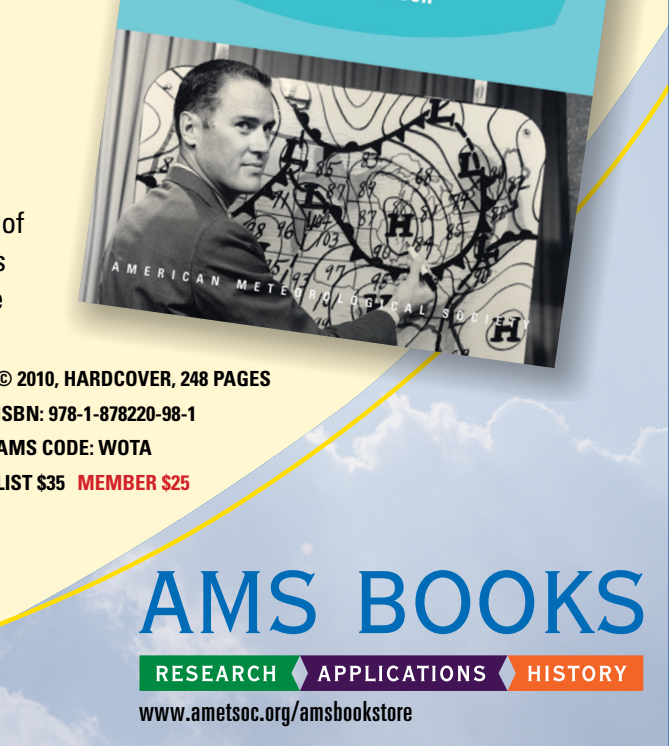


New Benefit for AMS Members!

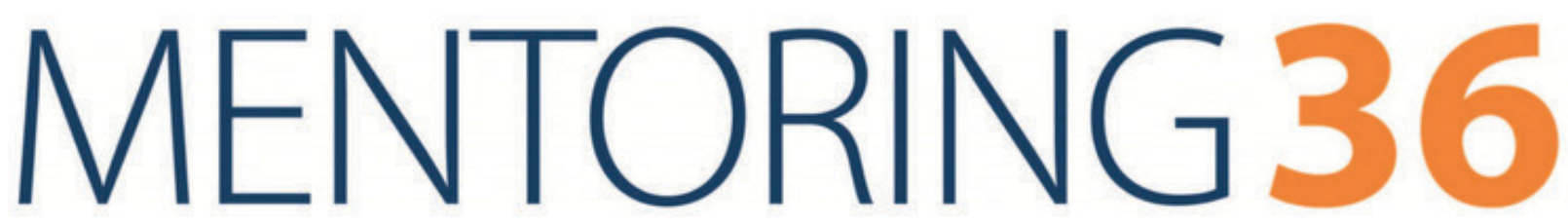

\section{Reach Your Full Potential}

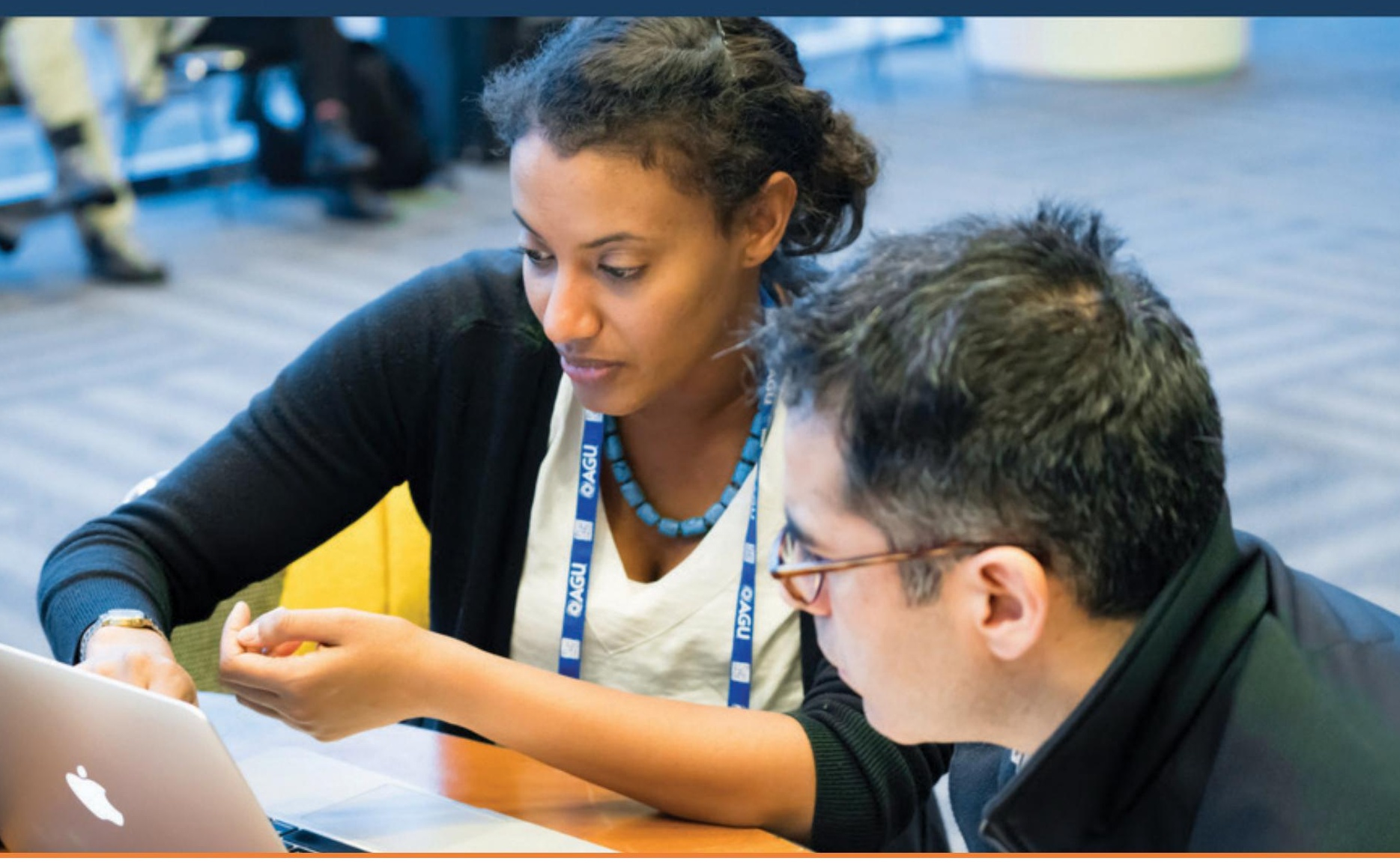

Developed in partnership with Earth and space science organizations, Mentoring365 provides mentors and mentees with structured relationship-building tools to develop and attain focused career goals.

(9) AMS www.mentoring365.org 